\title{
Orange-derived and lemon-derived adsorbents with controlled grain for an efficient elimination of some cationic and anionic dyes
}

\begin{abstract}
Purpose

The study aims to demonstrate that orange-derived and lemon-derived systems can be used in continuous processes as efficient adsorbents to the entrapment of some anionic and cationic dyes in the textile dyeing wastewater effluents.

\section{Desing/methodology/approach}

Physically and chemically modified orange and lemon mesocarps are used as natural adsorbents for the cationic dyes Basic Blue 3, Basic Yellow 21, Basic Red 18 and Basic Green 4 and, the anionic dyes Acid Blue 264, Acid Yellow 49 and Acid Red 337; all commonly used in the textile dyeing industry. Adsorption capacities of the orangederived and lemon-derived adsorbents on the dyes are studied simulating a batch and continuous industrial processes.

\section{Findings}

Results demonstrate that treated orange mesocarp (orange-derived adsorbent) can adsorb up to $97 \%$ of cationic Basic Green 4 in 30 min while the lemon mesocarp (lemon-derived adsorbent) can retain up to $88 \%$ within the same time. In the case of anionic, 91\% Acid Blue 264 is adsorbed by the orange mesocarp in 15 min whereas a $92 \%$ is adsorbed by the lemon homologue within the same time.

\section{Originality/value}

As far as we know, physically and chemically modified orange and lemon mesocarps have not been used on the removal of cationic (Basic Blue 3, Basic Yellow 21, Basic 
Red 18 and Basic Green 4) and anioinic (Acid Blue 264, Acid Yellow 49 and Acid Red 337) dyes of textile dyeing wastewater industry. It is a costless and efficient treatment that supposes, on the one hand, an ecofriendly and feasible process for discolouration of wastewater and, on the other, a valorisation (upcycling) of orange and lemon peels, which are not currently used.

KEYWORDS: cationic dye, anionic dye, adsorbent, adsorption, citrus peel, wastewater, textile dyeing

\section{Introduction}

One of the main drawbacks of the textile dyeing industry is the generation of large amounts of wastewater. This wastewater is rich in colour (dye) and in chemicals like surfactants, salts, alkalis and other hard-degradation and organic compounds that result in high-concentrated COD and BOD effluents (Hauser, 2011). The environmental impact includes solids in suspension, ionic charge, toxicity, oxygen concentration and colourisation. Generally, most dyes are very persistent in wastewaters due to their solubility and low degradation degree both determined by the complexity of their structure (Buitrón et al., 2004). It is estimated that approximately 100 tonnes/year of dyes are discharged into water and about $70 \%$ are azo type dyes (Gupta and Suhas, 2009; Ihsanullah et al., 2020). With the aim to discolour streams, several techniques have been investigated, including chemical (oxidation, electrolysis) (Corona-Bautista et al., 2021; Pacheco-Álvarez et al., 2019; Suhadolnik et al., 2019), ozonation (Abrile et al., 2020), physical (reverse osmosis, filtration, coagulation/flocculation, adsorption) (Ahmad et al., 2015; Al-Aoh, 2021; Paixão et al., 2020), combination of chemical and physical (Rezaee et al., 2008) and even biological (microorganisms, enzymes) processes (Arabaci and Usluoglu, 2014; Garg and Tripathi, 2017; Saratale et al., 2011). The 
majority of those operations incur in, among others, elevated maintenance level and manpower with high expertise that affect the final cost of the process and the profitability of the production (Donkadokula et al., 2020; Hauser, 2011; Soares et al., 2017).

Among all the water discoloration techniques, adsorption emerges as an economic alternative and a low environmental impact process (Liu et al., 2020; Rashed, 2013). The adsorption mechanism is based in the capture or retention of a compound (adsorbate) in a liquid phase by a solid (adsorbent) (Mostafa et al., 2009; Park et al., 2010). In this sense, a wide range of low-cost materials have been studied to be used as potential adsorbents for dyes such as wood (Kelm et al., 2019; Naeem and Hassan, 2018), clay (Kausar et al., 2018), ashes (Mor et al., 2018), activated muds (Qu et al., 2012; Sarvajith et al., 2018), orange (Namasivayam et al., 1996), cuttlefish bones (Elwakeel et al., 2020), algae (Elgarahy et al., 2020) and banana peels (Temesgen et al., 2018). In these recent years, the concepts of reuse and recycling have taken an important role in our society and resulted in an increase in research and development in sustainable technologies. For this reason, the current trend is to use agroindustrial wastes as alternative to produce new adsorbent materials due to their low cost and efficiency in the elimination of metal ions (Fu and Wang, 2011; Mo et al., 2018; Vijayaraghavan and Balasubramanian, 2015).

Part of the transformation of agroindustrial by-products such as orange and lemon peels into new raw materials, concretely into dye adsorbents, has been performed by CRESCA research group. In this sense, previous studies demonstrated satisfactory results in the use of mesocarps of orange and lemon into the adsorption of organic dyes as alternative for textile industry wastewater treatment (Arjona et al., 2018) or even as wine clarifiers (García-Raurich et al., 2019). 
Here, the evaluation of the adsorption capacity of modified mesocarps of orange and lemon peels to retain cationic and anionic dyes from textile dyeing industry wastewaters is presented. The adsorption capacity of the resulting adsorbents is tested in batch and in continuous processes with different cationic and anionic dyes, simulating industrial operations. Parameters such as the nature of the adsorbent, the concentration of the adsorbent, $\mathrm{pH}$ of the adsorption process, time of contact, hydration degree and number of column pass are evaluated by analysing the concentration of the dye in the residual liquor fraction by UV-Vis spectroscopy.

\section{Materials and methods}

\section{Materials}

Orange and lemons peels were collected from local fruit stores. Cationic dyes: Basic Blue $3\left(\mathrm{C}_{20} \mathrm{H}_{26} \mathrm{ClN}_{3} \mathrm{O}\right)$ (Blue), Basic Yellow $21\left(\mathrm{C}_{22} \mathrm{H}_{25} \mathrm{ClN}_{2}\right)$ (Yellow), Basic Red $18\left(\mathrm{C}_{19} \mathrm{H}_{25} \mathrm{Cl}_{2} \mathrm{~N}_{5} \mathrm{O}_{2}\right)$ (Red) and Basic Green $4\left(\mathrm{C}_{23} \mathrm{H}_{25} \mathrm{ClN}_{2}\right)$ (Green). Anionic dyes: Acid Blue $264\left(\mathrm{C}_{29} \mathrm{H}_{28} \mathrm{~N}_{3} \mathrm{NaO}_{6} \mathrm{~S}_{2}\right)$ (Blue), Acid Yellow $49\left(\mathrm{C}_{16} \mathrm{H}_{12} \mathrm{Cl}_{2} \mathrm{~N}_{5} \mathrm{O}_{3} \mathrm{~S}\right)$ (Yellow) and Acid Red $337\left(\mathrm{C}_{17} \mathrm{H}_{11} \mathrm{~F}_{3} \mathrm{~N}_{3} \mathrm{NaO}_{4} \mathrm{~S}\right)$ (Red) (Fig. 1). Dyes were purchased from Classic Dyestuffs Inc. Filters of $0.45 \mu \mathrm{m}$ pore of Millex were used in the batch process.

Fig. 1 a) Basic Blue 3, b) Basic Yellow 21, c) Basic Red 18, d) Basic Green 4, e) Acid Blue 264, f) Acid Yellow 49 and, g) Acid Red 337.

\section{Physical treatment of peels}

Washing of the orange and lemon peels was carried out with tap water and conventional soap at room temperature to eliminate added waxes, resins and soil of the epicarp. After drying with continuous air flow, mesocarps were cut using an ice mincer until achieve $0.5-1 \mu \mathrm{m}$ particle sizes, according to previous studies (Arjona et al., 2018). 


\section{Chemical treatment of peels}

Due to the different nature of the studied dyes, two different chemical treatments were applied to peels. With the objective to achieve an adsorbent capable to adsorb anionic dyes, the procedure was:

1. Acidic treatment: to remove pectins and other compounds such as $\beta$ carotene $(50 \mathrm{~g}$ peel/ $500 \mathrm{~mL}$ deionised water, $\mathrm{pH}=3-4$, ultrasonic agitation, $45 \mathrm{~min})$.

2. Alkaline treatment: saponification of peels, concretely cellulose, hemicellulose and remaining pectin fraction $\left(50 \mathrm{~g}\right.$ peel, $2.5 \mathrm{~g} \mathrm{Ca}(\mathrm{OH})_{2}$ (Panreac), the necessary volume of deionised water, $\mathrm{pH}>10$, ultrasonic agitation, $45 \mathrm{~min})$.

3. Acidic treatment: modification of ionic charge $(50 \mathrm{~g}$ peel/ $500 \mathrm{~mL}$ deionised water, $\mathrm{pH}=3-4$, ultrasonic agitation, $45 \mathrm{~min}$ ).

4. Neutralisation

5. Dry

The third step was avoided when peels were prepared to adsorb cationic dyes.

\section{Batch process}

In the discontinuous or batch process, the amount of adsorbent $(0.50,0.75$ and $1.00 \mathrm{~g})$, type of dye (anionic and cationic), concentration of dye (30, 60, 90, 120 and $240 \mathrm{ppm}), \mathrm{pH}$ (as-it-is, acid and alkaline), adsorption time $(5,10,15,30$ and $45 \mathrm{~min}$ for anionic and 15, 30, 45, 60 and 75 min for cationic) and the initial hydration degree of orange and lemon adsorbent parameters were studied. To do this, $25 \mathrm{~mL}$ of a solution of dye was prepared and mixed with the corresponding adsorbent at $20^{\circ} \mathrm{C}$. Then, the sample was filtered and the concentration of dye in the liquor was analysed by UV-Vis (Shimadzu UV-1800). 


\section{Continuous process}

Continuous process conditions were set once the conditions of the batch process were established. For this reason, only the dyes that presented the highest adsorption percentage in the batch process were tested in the continuous one (cationic green and anionic blue). Moreover, two types of columns were evaluated, a small column Afora $5831\left(\mathrm{n}^{\circ} 0\right.$ porous plate, glass key with $2 / 3 \mathrm{~mm}$ key passage, $10 \mathrm{~mm}$ internal diameter, $200 \mathrm{~mm}$ useful length) and a larger column Afora $5855\left(\mathrm{n}^{\circ} 0\right.$ porous plate, glass key with $2 / 3 \mathrm{~mm}$ key pass, $30 \mathrm{~mm}$ internal diameter and $500 \mathrm{~mm}$ useful length). The first column was used to perform experiments towards the determination of the evolution of the adsorbent adsorptions to the column pass volume ( $5 \mathrm{~g}$ of adsorbent, $30 \mathrm{ppm}$ dye solution, $25 \mathrm{~mL} / \mathrm{min}$, recovered adsorbent was washed with ethyl alcohol) and, the second, to determine the influence of the flow rate $(125,43$ and $23 \mathrm{~mL} / \mathrm{min}$ for $20 \mathrm{~g}$ of adsorbent) together with the concentration of dye (20 g adsorbent with 30 and $60 \mathrm{ppm}$ of dye) in the dye adsorption yield.

\section{All methods were carried out in accordance with relevant guidelines and regulations}

\section{Results and discussion}

\section{Batch process}

The influence of the amount of the chemically and physically treated orange and lemon peels (adsorbents) to the cationic dyes adsorption was firstly evaluated. To do this, cationic dyes were initially analysed by UV-Vis absorption spectroscopy in order to obtain the wavelengths corresponding to the peaks of maximum absorption. The resulting spectra indicated that the maximum absorption signal for each one of the cationic dyes were found at $652 \mathrm{~nm}, 488 \mathrm{~nm}, 415.5$ and $613.5 \mathrm{~nm}$ for blue, red, yellow 
and green, respectively, and for anionic were found at $607 \mathrm{~nm}, 491 \mathrm{~nm}$ and $399 \mathrm{~nm}$ for blue, red and yellow, respectively. Afterwards, adsorption experiments with orangederived and lemon-derived adsorbents with the mentioned dyes were carried out. A clear liquid fraction was obtained after $45 \mathrm{~min}$ when $0.5,0.75$ and $1.00 \mathrm{~g}$ of orangederived and lemon-derived adsorbents where put in contact with cationic dye, indicating a high adsorption capacity of both adsorbents (Fig. 2).

Fig. 2 a) Orange-derived and b) lemon-derived adsorbents in different concentrations after adsorption process with cationic red dye.

Those liquid fractions or liquors where subsequently analysed by UV-Vis spectroscopy and the percentage of adsorbed dye was calculated for each amount of adsorbent used (Fig. 3).

Fig. 3 Percentages of adsorbed cationic dyes according to the amounts of (left) orange-derived and (right) lemon-derived adsorbents.

Similar adsorption values were obtained for orange-derived and lemon-derived adsorbents, however the overall percentage was slightly higher in the case of orangederived adsorbent. Blue, yellow and green cationic dyes where increasingly adsorbed with the concentration of both adsorbents, although a discreet increase of a $0.25 \%$ between 0.75 and $1.00 \mathrm{~g}$ of orange-derived adsorbent was spotted for the green. Concretely, in the case of yellow, differences in the adsorption were found in the nature of the adsorbent, being higher in the case of orange-derived. Contrastingly, red cationic dye was similarly adsorbed for both adsorbents, presumably indicating an important correlation between the chemical nature of the dyes to the adsorption results. 
Furthermore, the capacity of the orange-derived and lemon-derived adsorbents was extensively evaluated with anionic dyes (Fig. 4).

Fig. 4 Percentages of adsorbed anionic dyes according to the amounts of (left) orange-derived and (right) lemon-derived adsorbents.

In contrast to the results obtained for cationic, blue anionic dye was highly retained by the lemon-derived adsorbent rather the orange-derived, presenting an averaged difference of the $31.66 \%$. Nevertheless, the concentration of adsorbent was essentially an independent parameter when values were compared within the same adsorbent for this dye. On the other hand, the percentage of red anionic dye adsorbed increased with the amount of adsorbent, similarly to yellow anionic dye. However, yellow anionic dye was the only dye that showed a higher retention with orange-derived adsorbent than the other one. Those observed differences in the adsorption with the different dyes may have probably been influenced by the stereochemistry of the molecule of the dye due to the position and the steric hindrance of the reactive groups in each case. Moreover, an amount of $1.00 \mathrm{~g}$ of adsorbent was established to be the more suitable concentration on dye adsorption and so, subsequent experiments were set with this parameter.

The influence of the dye concentration in the adsorption capacity of the adsorbents was also evaluated maintaining at $1.00 \mathrm{~g}$ the amount of the adsorbent. The assay was performed with the dyes that showed the strongest and the weakest adsorption affinity to the adsorbents. Thus, green and yellow cationic dyes and blue and yellow anionic dyes were tested with different initial concentrations, ranging from 30 to 240 ppm (Table 1). 
Table 1 Percentages of adsorbed dyes according to its initial concentration for orange-derived and lemon-derived adsorbents.

Both, orange-derived and lemon-derived adsorbents did not exhibit significant differences in the adsorption of green cationic dye, resulting in high adsorption efficiencies even at the higher concentrations. On the contrary, yellow cationic dye experienced the maximum retention between 90 and 120 ppm for both adsorbents, and then a moderate decay at higher dye concentrations. Due to the poorer affinity between yellow cationic dye and the adsorbents respect to the green homologue, a major quantity of the yellow was necessary to achieve similar adsorption results as green, in concordance with previous observations. In the case of anionic dyes, orange-derived adsorbent experienced a maximum adsorption peak at $90 \mathrm{ppm}$ of blue dye, however at higher concentrations a progressive decreasing of this adsorption was spotted. On the other hand, when lemon-derived adsorbent was put in contact with blue anionic dye, an almost lineal decrease between 30 and 120 ppm could be observed $(\mathrm{y}=$ $\left.0.3003 x+102.2, R^{2}=0.97\right)$, indicating the highest adsorption efficiency at the lowest dye concentration. As expected due to the previous results, yellow anionic dye showed discreet adsorption results for both types of adsorbent, presenting a maximum at 60 ppm. Even though, the following assays were performed with a concentration of $30 \mathrm{ppm}$ of dye.

Another parameter that may greatly influence the capacity of dye adsorption of adsorbents is the $\mathrm{pH}$ value. For this reason, adsorption experiments were carried out, 
comparing different $\mathrm{pH}$ values: as-it-is, acid $(\mathrm{pH}=4$ and 2$)$ and alkaline $(\mathrm{pH}=10$ and 12) (Fig. 5).

Fig. 5 Percentages of adsorbed (top) cationic and (bottom) anionic dyes according to the different $p H$ values for (left) orange-derived and (right) lemon-derived adsorbents.

Experiments with cationic dyes revealed that the capacity to adsorb red and green dyes was not significantly affected by the $\mathrm{pH}$. However, blue and yellow dyes were greatly retained with an unmodified $\mathrm{pH}$ value, as-it-is, by both adsorbents. Orange-derived adsorbent resulted in higher values of adsorption when the nature of adsorbent was compared. Furthermore, in the case of anionic dyes, the adsorption capacity experienced a progressive decrease with the increase of the $\mathrm{pH}$ values for red and yellow dyes. On the other hand, the percentage of adsorbed blue dye kept almost invariable along the different values of $\mathrm{pH}$. Contrary to the cationic, anionic dyes were better adsorbed by the lemon-derived adsorbent. Because in the most cases higher absorption results were obtained by the $\mathrm{pH}$ as-it-is, the two-type adsorbents with unmodified $\mathrm{pH}$ were concluded to be the most suitable for dye adsorption.

Moreover, the adsorption time or the contact time between the adsorbent and the dye solution was also determined. Adsorption times were different according to the nature of the dyes because previous results demonstrated a faster adsorption of anionic dyes than cationic. Both, orange-derived and lemon-derived adsorbents could retain an initial increasing percentage of cationic dyes within the first 30 min and then, a plateau appeared (Fig. 6). Similar behaviour was observed in the case of anionic dyes, however the plateau appeared after $15 \mathrm{~min}$ of contact time. 
Fig. 6 Percentages of adsorbed (top) cationic and (bottom) anionic dyes according to the different contact times for (left) orange-derived and (right) lemon-derived adsorbents.

Within cationic dyes, green was the fastest and the highest percentage dye that was adsorbed by both adsorbents and yellow the lesser in all senses, in concordance with previous observed results. On the other hand, blue and yellow anionic dyes experienced a similar behaviour as the adsorption affinity assays exposed above, being the more and faster adsorbed the blue, and the lesser and slowest the yellow. Those differences were presumably related with the chemical structure and steric hindrance of the reactive groups of the dyes. Contact times of $30 \mathrm{~min}$ for cationic dyes and $15 \mathrm{~min}$ for anionic dyes were established to be suitable to obtain adequate adsorptivities with those adsorbents.

All experiments were carried out using dried orange-derived and lemon-derived adsorbents. Nevertheless, the influence of the hydration degree of the adsorbents to the capacity of adsorption was determined. To do this, same experiments performed for the determination of the adequate contact time between adsorbent and dyes were repeated with hydrated adsorbents. With the objective to achieve a 'hydrated' state, adsorbents were left in contact with distilled water $24 \mathrm{~h}$ before conducting the assay. Results demonstrated that hydrated adsorbents could retain more effectively cationic and anionic dyes, especially in the case of yellow dyes, whose affinities to the dry adsorbents were the weakest (Fig. 7). This observation could be related with the capacity to form hydrogen bonds between water and surrounding dye molecules. Optimal contact times and its behaviour appeared to be the same for hydrated than for dry adsorbents. Consequently, hydrated adsorbent was concluded to be the most suitable state to the adsorption of cationic and anionic dyes. 
Fig. 7 Percentages of adsorbed (top) cationic and (bottom) anionic dyes according to the different contact times for (left) hydrated orange-derived and (right) hydrated lemon-derived adsorbents.

\section{Continuous process}

The determination of the adsorption capacities of orange-derived and lemonderived adsorbents in a continuous process were developed after the optimum conditions were established in a batch process. Continuous process experiments were conducted using the dyestuffs that presented the highest adsorption percentages in the batch process and so, green as cationic dye and blue as anionic were tested. First, an experiment to determine the evolution of adsorption of the adsorbents according to the volume that passes through was conducted in a small column. The eluted fluid from the column was collected and used in a second elution through the recovered adsorbent, simulating the effect of a second column in series. This process was repeated a third time, simulating a third column in series. The capacity of adsorption of the adsorbents decreased as the elutions of dyestuffs developed, as expected, indicating a decrease of the adsorption yield (Fig. 8). In the case of green cationic dye, after the first elution or column, the percentage of adsorbed dye was reduced down to an $18 \%$ when orangederived adsorbent was used and until a $2 \%$ with the lemon-derived. However, this percentage of dye adsorbed increased up to $76 \%$ and to $19 \%$ for orange-derived and lemon-derived, respectively, when the adsorbent was recovered and passed through a second serial column. At the end of the third elution, the amount of dye adsorbed raised up to $90 \%$ in the case of the orange-derived adsorbent and up to $59 \%$ in the case of the lemon-derived homologue. A preferentially adsorption of the cationic dyes by orangederived adsorbent could be concluded. 
Fig. 8 Percentages of adsorbed of (top) green cationic dye and (bottom) blue anionic dye vs. the volume of elution for (left) orange-derived and (right) lemon-derived adsorbents.

On the other hand, a $20 \%$ of blue anionic dye could be adsorbed by the orangederived adsorbent, similarly to the lemon-derived, which was $18 \%$ (Fig. 8). Afterwards, the second column was able to retain up to $48 \%$ and $47 \%$ of dye when orange-derived and lemon-derived where used as adsorbents, respectively. Finally, after the third elution, the capacity of the orange-derived and lemon-derived adsorbents increased up to $67 \%$ and $71 \%$, respectively. In contrast to cationic dyes, anionic dyes did not show significant contrast in adsorptivity values when the different types of adsorbent where compared.

Additionally, the evolution of the adsorption capacity of the adsorbents was investigated at different flow rates. This part of the study was performed with green cationic dye and orange-derived adsorbent due to the promising obtained results. Similarly to the previous part, three serial columns disposition was simulated, so the fluid recovered at the end of the first column pass was sequentially passed again two more times. Although the maximum flow rate studied presented an adsorption of $90 \%$, the elution was not stable (Table 2). The stabilisation of the elution was achieved at 23 $\mathrm{mL} / \mathrm{min}$, where a $100 \%$ of the dye was adsorbed at the $2^{\text {nd }}$ column. Starting from the minimum flow rate, this was progressively increased until a decreasing of the adsorption was not observed together with a stable elution. In this way, $43 \mathrm{~mL} / \mathrm{min}$ was found to be the more balanced flow rate.

Table 2 Percentages of adsorbed dye according to the flow rate and column pass. 
Once the flow rate was established, the adsorption capacity of the adsorbents was evaluated at different green cationic and blue cationic dyes concentration in order to observe differences in the adsorption yield. Results showed that, excepting for the elution of the green dye with lemon-derived adsorbent, more promising results were obtained when the concentration of the dye was $60 \mathrm{ppm}$ (Table 3). Thus, the concentration of dye with the utmost efficiency of the adsorbent could be established. Moreover, higher adsorption percentages were obtained with orange-derived adsorbent when the nature of adsorbents was compared within the same cationic dye. Contrastingly, the most suitable type of adsorbent to retain anionic dye was the lemonderived, in concordance with the previous observed results.

Table 3 Percentages of adsorbed dyes according to the initial dye concentration for each type of adsorbent and column pass.

\section{Conclusions}

In this manuscript, the successful use of orange-derived and lemon-derived peels as adsorbents after some treatments to the adsorption of cationic and anionic dyes from textile dyeing wastewater has been demonstrated. The study has been conducted simulating two industrial processes, a batch and a continuous. From the batch process, a concentration of dye of $30 \mathrm{ppm}$, without the modification of the dyestuff, contact times between the dye and adsorbent of $30 \mathrm{~min}$ for cationic dyes and $15 \mathrm{~min}$ for anionic together with a hydrated adsorbent were the most favourable conditions. Moreover, the behaviour of orange-derived and lemon-derived adsorbents for cationic dyes has converged at concentrations of dye above $30 \mathrm{ppm}$. 
In the case of the continuous process, the most suitable conditions of flow rate have been found at $43 \mathrm{~mL} / \mathrm{min}$, being the orange-derived adsorbent the more promising for cationic dyes and lemon-derived for anionic dyes. Furthermore, it has been demonstrated that the column efficiency increased with the dyed wastewater concentration, exhibiting an increase of the double of the adsorption of dye when the initial concentration increased from $30 \mathrm{ppm}$ to $60 \mathrm{ppm}$ for cationic dyes and more than four times with the yellow anionic dye. Finally, the recovery of the adsorbed dye by ethyl alcohol, allowing the regeneration of the column until seven times at least has been also demonstrated.

This study is a contribution to the circular economy since it takes advantage of agricultural wastes from the industry of juice production to transform them into bioderived adsorbents towards the purification of coloured wastewaters from dyeing textile materials.

\section{Disclosure statement}

No potential conflict of interest was reported by the authors.

\section{References}

Abrile, M.G., Fiasconaro, M.L. and Lovato, M.E. (2020), “Optimization of Reactive Blue 19 dye removal using ozone and ozone/UV employing response surface methodology”, SN Applied Sciences, Vol. 2 No. 5, p. 995.

Ahmad, A., Mohd-Setapar, S.H., Chuong, C.S., Khatoon, A., Wani, W.A., Kumar, R. and Rafatullah, M. (2015), "Recent advances in new generation dye removal technologies: novel search for approaches to reprocess wastewater", $R S C A d v$., The Royal Society of Chemistry, Vol. 5 No. 39, pp. 30801-30818. 
Al-Aoh, M.A. and J.A. and A.A. and A.A. and N.A. and A.A. and Q.A. and A.K. and A.A. and H.A. (2021), "Efficient dye discoloration of modified Lamiaceae leaves", Materials Research Express, available at:

http://iopscience.iop.org/article/10.1088/2053-1591/abeb8f.

Arabaci, G. and Usluoglu, A. (2014), “The Enzymatic Decolorization of Textile Dyes by the Immobilized Polyphenol Oxidase from Quince Leaves”, edited by Çakar, Z.P. and Talat, M.The Scientific World Journal, Hindawi Publishing Corporation, Vol. 2014, p. 685975.

Arjona, A., Canal, J.M. and García Raurich, J. (2018), “A new biosorbent with controlled grain (I). Efficient elimination of cationic dyes from textile dyeing wastewater", IJOEAR, Vol. 4 No. 3, pp. 14-27.

Buitrón, G., Quezada, M. and Moreno, G. (2004), “Aerobic degradation of the azo dye acid red 151 in a sequencing batch biofilter", Bioresource Technology, Vol. 92 No. 2, pp. 143-149.

Corona-Bautista, M., Picos-Benítez, A., Villaseñor-Basulto, D., Bandala, E. and Peralta-Hernández, J.M. (2021), “Discoloration of azo dye Brown HT using different advanced oxidation processes”, Chemosphere, Vol. 267, p. 129234.

Donkadokula, N.Y., Kola, A.K., Naz, I. and Saroj, D. (2020), “A review on advanced physico-chemical and biological textile dye wastewater treatment techniques", Reviews in Environmental Science and Bio/Technology, Vol. 19 No. 3, pp. 543560.

Elgarahy, A.M., Elwakeel, K.Z., Mohammad, S.H. and Elshoubaky, G.A. (2020), "Multifunctional eco-friendly sorbent based on marine brown algae and bivalve shells for subsequent uptake of Congo red dye and copper(II) ions", Journal of Environmental Chemical Engineering, Vol. 8 No. 4, p. 103915. 
Elwakeel, K.Z., Elgarahy, A.M., Elshoubaky, G.A. and Mohammad, S.H. (2020), "Microwave assist sorption of crystal violet and Congo red dyes onto amphoteric sorbent based on upcycled Sepia shells", Journal of Environmental Health Science and Engineering, Vol. 18 No. 1, pp. 35-50.

Fu, F. and Wang, Q. (2011), "Removal of heavy metal ions from wastewaters: A review", Journal of Environmental Management, Vol. 92 No. 3, pp. 407-418.

García-Raurich, J., Vázquez-Ricard, A., Pallarès-Andreu, M., Monagas Asensio, P. and Almajano Pablos, M.P. (2019), “Application of Citrus Bioadsorbents as Wine Clarifiers", International Journal of Environmental \& Agriculture Research, Vol. 3 No. 5, pp. 1-11.

Garg, S. and Tripathi, M. (2017), "Microbial Strategies for Discoloration and Detoxification of Azo Dyes from Textile Effluents", Research Journal of Microbiology, Vol. 12, pp. 1-19.

Gupta, V.K. and Suhas. (2009), “Application of low-cost adsorbents for dye removal A review", Journal of Environmental Management, Vol. 90 No. 8, pp. 2313-2342. Hauser, P. (2011), Advances in Treating Textile Effluent, IntechOpen, available at: https://books.google.es/books?id=2XuQDwAAQBAJ.

Ihsanullah, I., Jamal, A., Ilyas, M., Zubair, M., Khan, G. and Atieh, M.A. (2020), "Bioremediation of dyes: Current status and prospects", Journal of Water Process Engineering, Vol. 38, p. 101680.

Kausar, A., Iqbal, M., Javed, A., Aftab, K., Nazli, Z.-H., Bhatti, H.N. and Nouren, S. (2018), "Dyes adsorption using clay and modified clay: A review", Journal of Molecular Liquids, Vol. 256, pp. 395-407.

Kelm, M.A.P., da Silva Júnior, M.J., de Barros Holanda, S.H., de Araujo, C.M.B., de Assis Filho, R.B., Freitas, E.J., dos Santos, D.R., et al. (2019), "Removal of azo 
dye from water via adsorption on biochar produced by the gasification of wood wastes”, Environmental Science and Pollution Research, Vol. 26 No. 28, pp. $28558-28573$.

Liu, Y., Zhao, Y., Cheng, W. and Zhang, T. (2020), “Targeted reclaiming cationic dyes from dyeing wastewater with a dithiocarbamate-functionalized material through selective adsorption and efficient desorption", Journal of Colloid and Interface Science, Vol. 579, pp. 766-777.

Mo, J., Yang, Q., Zhang, N., Zhang, W., Zheng, Y. and Zhang, Z. (2018), “A review on agro-industrial waste (AIW) derived adsorbents for water and wastewater treatment", Journal of Environmental Management, Vol. 227, pp. 395-405.

Mor, S., Chhavi, M.K., Sushil, K.K. and Ravindra, K. (2018), “Assessment of hydrothermally modified fly ash for the treatment of methylene blue dye in the textile industry wastewater", Environment, Development and Sustainability, Vol. 20 No. 2, pp. 625-639.

Mostafa, K.M., Samarkandy, A.R. and El-Sanabary, A.A. (2009), "Preparation of poly (MAA)-crosslinked pregelled starch graft copolymer and its application in waste water treatments", Journal of Applied Polymer Science, John Wiley \& Sons, Ltd, Vol. 112 No. 5, pp. 2838-2846.

Naeem, H. and Hassan, A. (2018), "Effectiveness \& economy of sawdust wood adsorbents in removing anionic dyes of aqueous solutions".

Namasivayam, C., Muniasamy, N., Gayatri, K., Rani, M. and Ranganathan, K. (1996), "Removal of dyes from aqueous solutions by cellulosic waste orange peel", Bioresource Technology, Vol. 57 No. 1, pp. 37-43.

Pacheco-Álvarez, M.O.A., Picos, A., Pérez-Segura, T. and Peralta-Hernández, J.M. (2019), "Proposal for highly efficient electrochemical discoloration and 
degradation of azo dyes with parallel arrangement electrodes”, Journal of Electroanalytical Chemistry, Vol. 838, pp. 195-203.

Paixão, R.M., Reck, I.M., da Silva, L.H.B.R., Baptista, A.T.A., Bergamasco, R., Vieira, M.F. and Vieira, A.M.S. (2020), "Discolouration of contaminated water with textile dye through a combined coagulation/flocculation and membrane separation process with different natural coagulants extracted from Moringa oleifera Lam. seeds", The Canadian Journal of Chemical Engineering, John Wiley \& Sons, Ltd, Vol. n/a No. n/a, available at:https://doi.org/https://doi.org/10.1002/cjce.23932.

Park, D., Yun, Y.-S. and Park, J.M. (2010), “The past, present, and future trends of biosorption”, Biotechnology and Bioprocess Engineering, Vol. 15 No. 1, pp. 86102.

Qu, Y., Cao, X., Ma, Q., Shi, S., Tan, L., Li, X., Zhou, H., et al. (2012), “Aerobic decolorization and degradation of Acid Red B by a newly isolated Pichia sp. TCL”, Journal of Hazardous Materials, Vol. 223-224, pp. 31-38.

Rashed, M.N. (2013), Adsorption Technique for the Removal of Organic Pollutants from Water and Wastewater, Organic Pollutants - Monitoring, Risk and Treatment, edited by IntechOpen, available at:https://doi.org/10.5772/54048.

Rezaee, A., Ghaneian, M.T., Hashemian, S.J. and Moussavi, G. (2008), "Photochemical oxidation of Reactive Blue 19 dye (RB19) in textile wastewater by UV/K2S2O8 process", Journal of Environmental Health Science \& Engineering, Vol. 2 No. 5, pp. $95-100$.

Saratale, R.G., Saratale, G.D., Chang, J.S. and Govindwar, S.P. (2011), "Bacterial decolorization and degradation of azo dyes: A review", Journal of the Taiwan Institute of Chemical Engineers, Vol. 42 No. 1, pp. 138-157.

Sarvajith, M., Reddy, G.K.K. and Nancharaiah, Y. V. (2018), “Textile dye 
biodecolourization and ammonium removal over nitrite in aerobic granular sludge sequencing batch reactors", Journal of Hazardous Materials, Vol. 342, pp. 536543.

Soares, P.A., Souza, R., Soler, J., Silva, T.F.C. V, Souza, S.M.A.G.U., Boaventura, R.A.R. and Vilar, V.J.P. (2017), "Remediation of a synthetic textile wastewater from polyester-cotton dyeing combining biological and photochemical oxidation processes", Separation and Purification Technology, Vol. 172, pp. 450-462.

Suhadolnik, L., Pohar, A., Novak, U., Likozar, B., Mihelič, A. and Čeh, M. (2019), “Continuous photocatalytic, electrocatalytic and photo-electrocatalytic degradation of a reactive textile dye for wastewater-treatment processes: Batch, microreactor and scaled-up operation", Journal of Industrial and Engineering Chemistry, Vol. 72, pp. $178-188$.

Temesgen, F., Gabbiye, N. and Sahu, O. (2018), "Biosorption of reactive red dye (RRD) on activated surface of banana and orange peels: Economical alternative for textile effluent”, Surfaces and Interfaces, Vol. 12, pp. 151-159.

Vijayaraghavan, K. and Balasubramanian, R. (2015), "Is biosorption suitable for decontamination of metal-bearing wastewaters? A critical review on the state-ofthe-art of biosorption processes and future directions", Journal of Environmental Management, Vol. 160, pp. 283-296. 
Orange-derived and lemon-derived adsorbents with controlled grain for an efficient elimination of some cationic and anionic dyes


d)<smiles>Nc1ccc(C(=C2CCC(N)CC2)c2ccccc2)cc1</smiles><smiles>COc1cc(C)c2c(c1N)C(C)c1ccccc1C2=O</smiles>

c)<smiles>CCCN(C)c1ccc(/N=N/c2ccc([N+](=O)[O-])cc2Cl)cc1</smiles>

f)

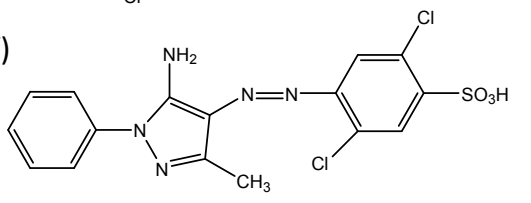

g)<smiles>COc1cccc(O)c1</smiles>

<smiles>Cc1cccc(N)c1N=Nc1ccccc1Br</smiles><smiles>C1CCCCC1</smiles>

Fig. 1 a) Basic Blue 3, b) Basic Yellow 21, c) Basic Red 18, d) Basic Green 4, e) Acid Blue 264, f) Acid Yellow 49 and, g) Acid Red 337.

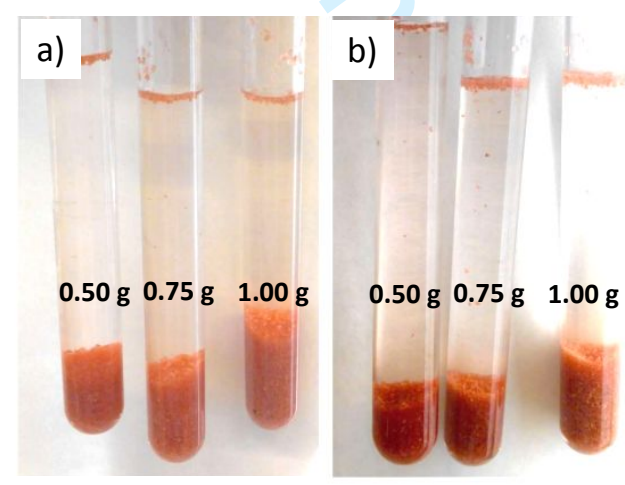

Fig. 2 a) Orange-derived and b) lemon-derived adsorbents in different concentrations after adsorption process with cationic red dye. 

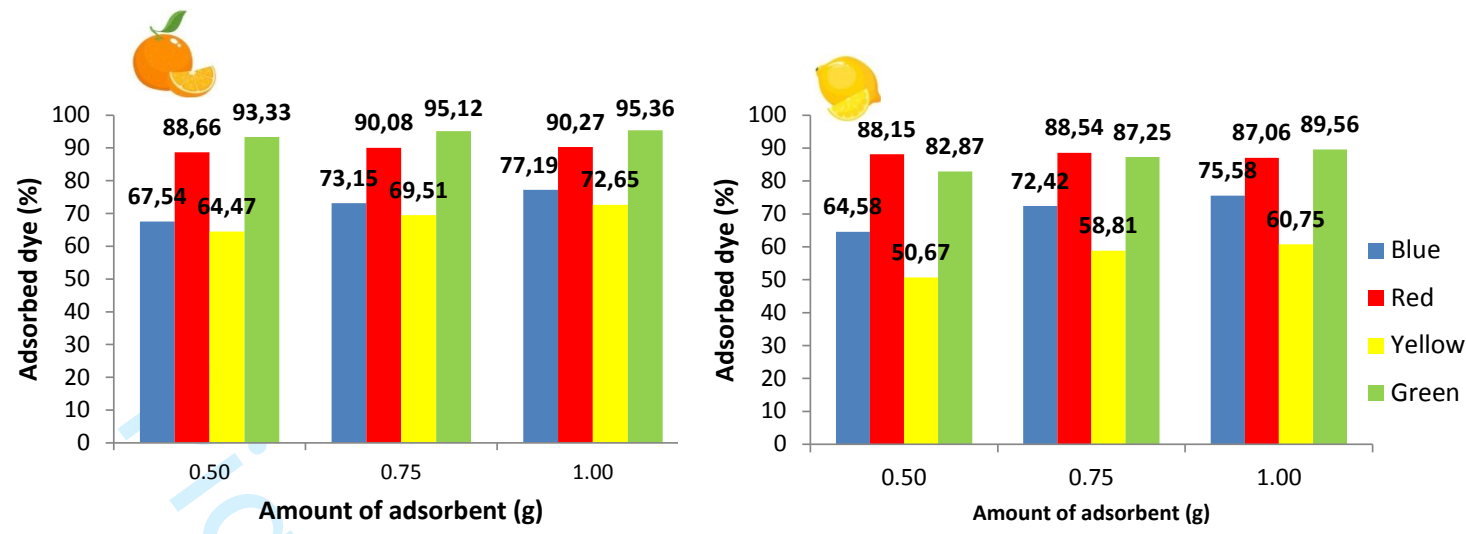

Fig. 3 Percentages of adsorbed cationic dyes according to the amounts of (left) orange-derived and (right) lemon-derived adsorbents.
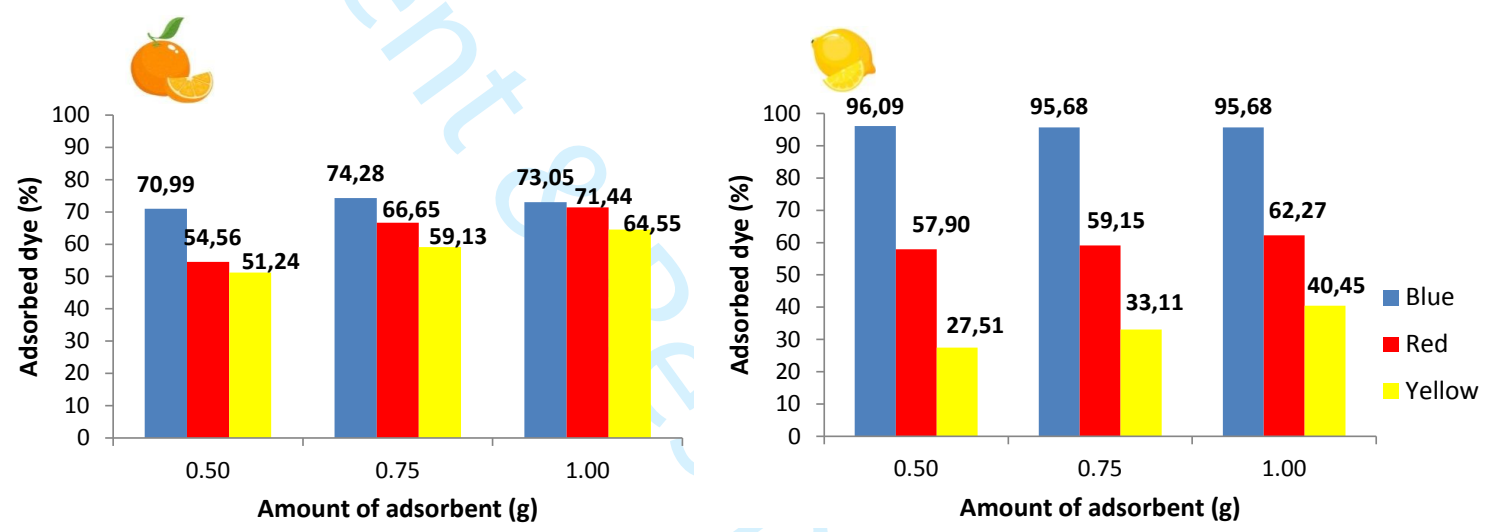

Fig. 4 Percentages of adsorbed anionic dyes according to the amounts of (left) orange-derived and (right) lemon-derived adsorbents. 



Fig. 5 Percentages of adsorbed (top) cationic and (bottom) anionic dyes according to the different $\mathrm{pH}$ values for (left) orange-derived and (right) lemon-derived adsorbents.
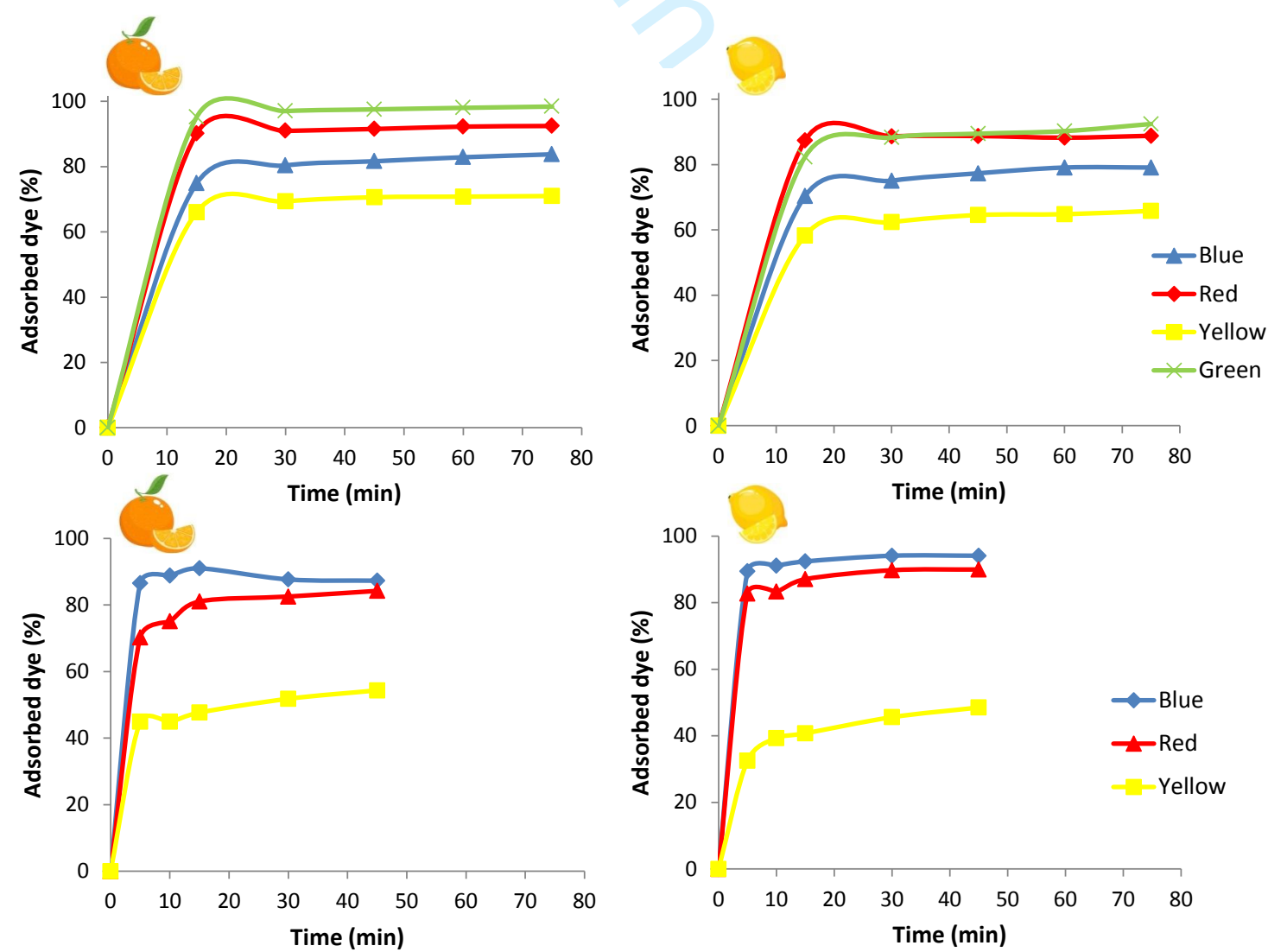
Fig. 6 Percentages of adsorbed (top) cationic and (bottom) anionic dyes according to the different contact times for (left) orange-derived and (right) lemon-derived adsorbents.
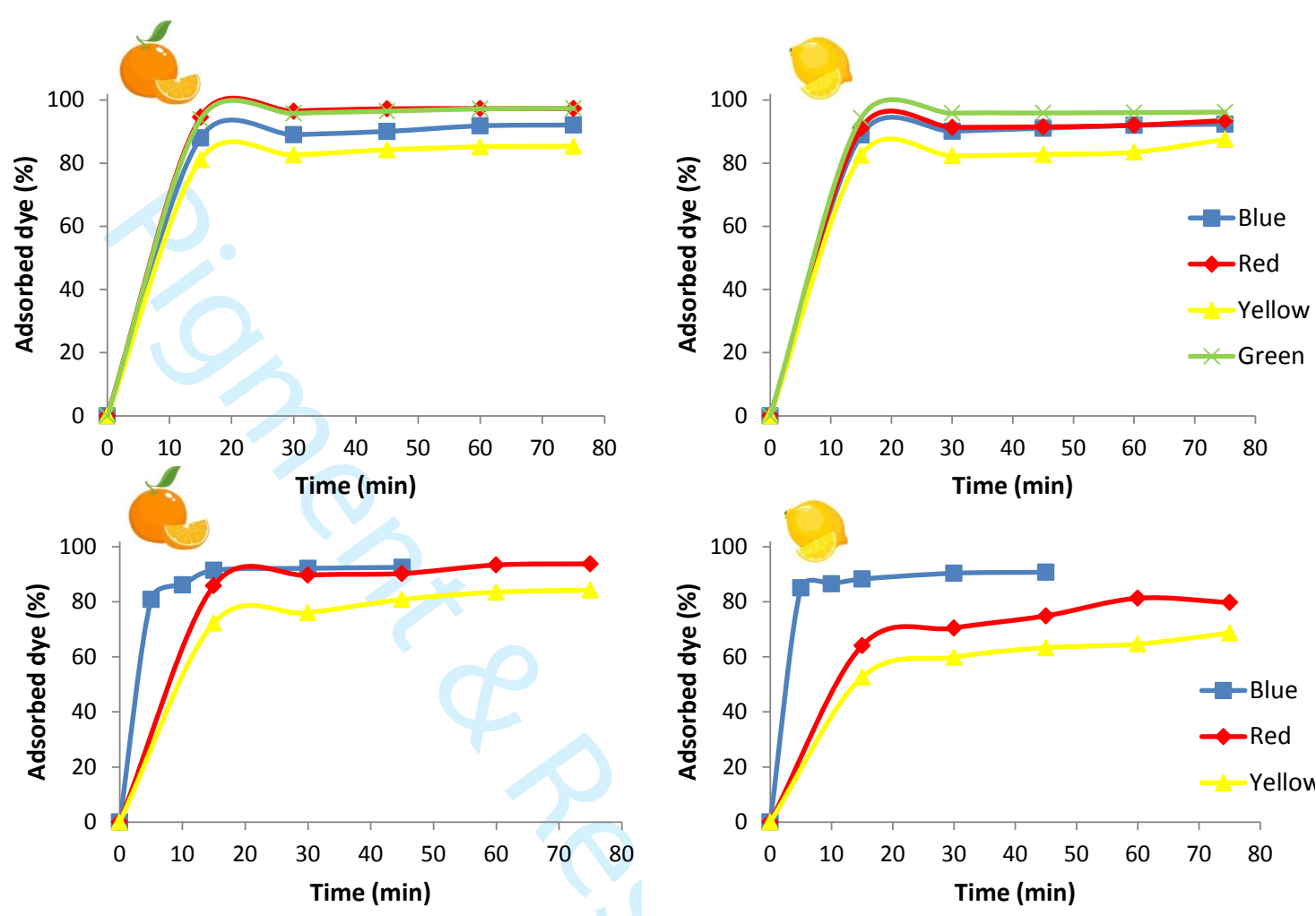

Fig. 7 Percentages of adsorbed (top) cationic and (bottom) anionic dyes according to the different contact times for (left) hydrated orange-derived and (right) hydrated lemon-derived adsorbents. 

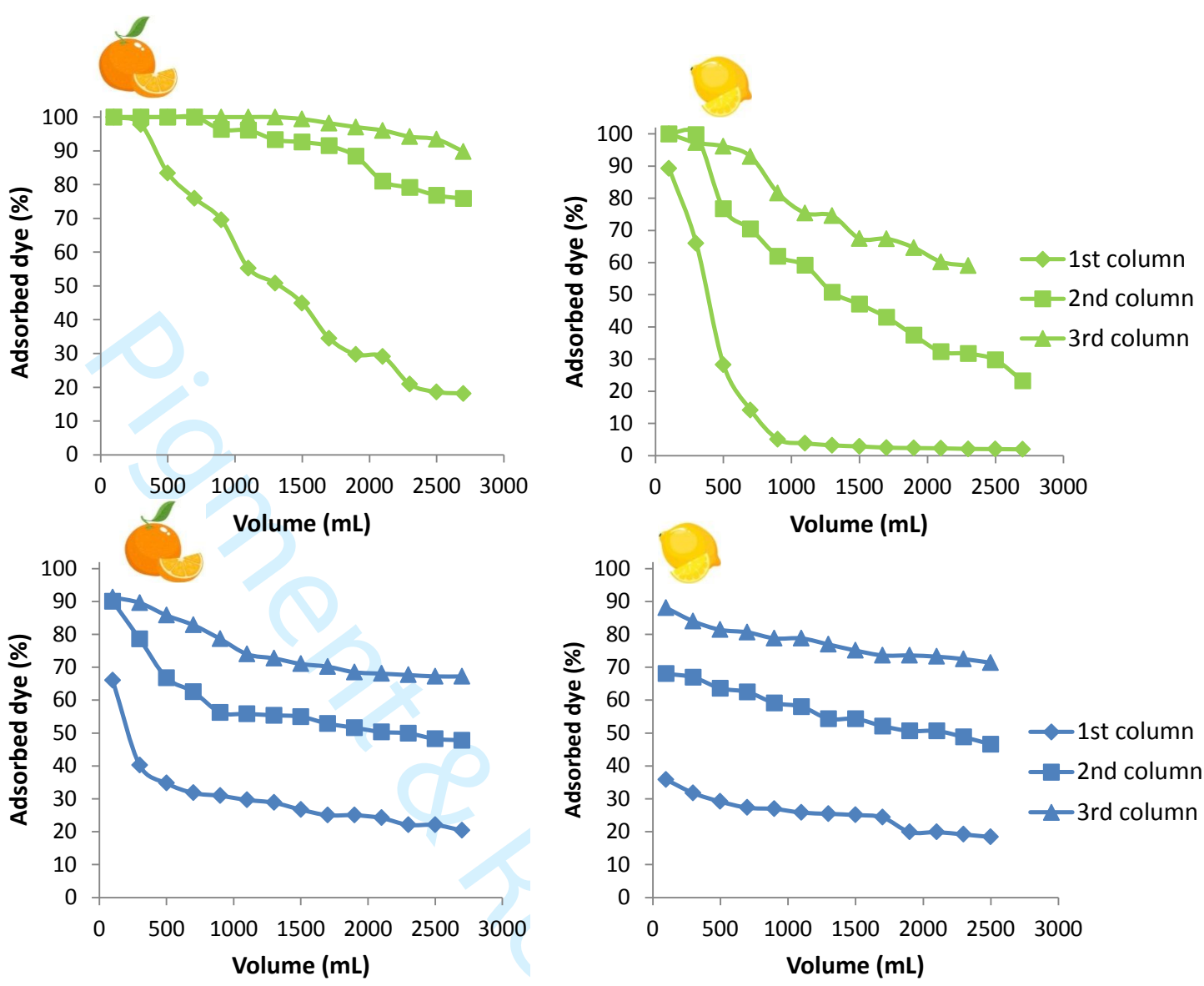

Fig. 8 Percentages of adsorbed of (top) green cationic dye and (bottom) blue anionic dye vs. the volume of elution for (left) orange-derived and (right) lemon-derived adsorbents. 
Orange-derived and lemon-derived adsorbents with controlled grain for an efficient elimination of some cationic and anionic dyes

Table 1 Percentages of adsorbed dyes according to its initial concentration for orange-derived and lemon-derived adsorbents.

\begin{tabular}{|c|c|c|c|c|c|c|c|}
\hline \multirow{2}{*}{$\begin{array}{c}\text { Type of } \\
\text { dye }\end{array}$} & \multirow{2}{*}{ Dye } & \multirow{2}{*}{ Adsorbent } & \multicolumn{5}{|c|}{ Initial concentration (ppm) } \\
\hline & & & 30 & 60 & 90 & 120 & 240 \\
\hline \multirow{4}{*}{ Cationic } & \multirow{2}{*}{ Green } & Orange & 96.30 & 96.17 & 96.64 & 97.59 & 96.72 \\
\hline & & Lemon & 96.30 & 96.17 & 96.64 & 97.59 & 97.85 \\
\hline & \multirow{2}{*}{ Yellow } & Orange & 72.65 & 97.57 & 98.31 & 98.75 & 81.91 \\
\hline & & Lemon & 60.75 & 98.81 & 99.04 & 99.33 & 91.56 \\
\hline \multirow{4}{*}{ Anionic } & \multirow{2}{*}{ Blue } & Orange & 71.5 & 91.9 & 94.3 & 88.3 & 85.3 \\
\hline & & Lemon & 95.0 & 81.7 & 74.7 & 67.3 & 69.7 \\
\hline & \multirow{2}{*}{ Yellow } & Orange & 48.0 & 84.8 & 79.2 & 68.0 & 65.9 \\
\hline & & Lemon & 40.4 & 70.4 & 60.2 & 36.3 & 43.7 \\
\hline
\end{tabular}

Table 2 Percentages of adsorbed dye according to the flow rate and column pass.

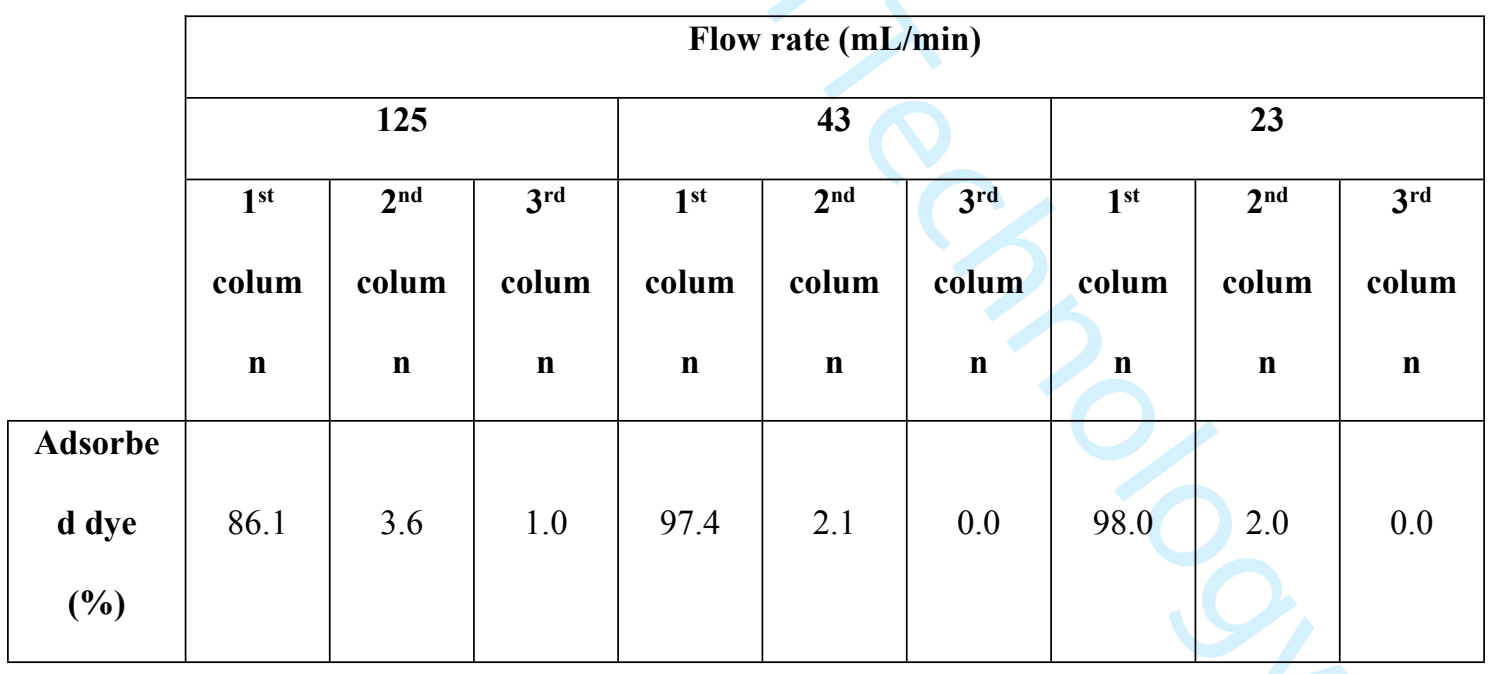

Table 3 Percentages of adsorbed dyes according to the initial dye concentration for each type of adsorbent and column pass.

Dye concentration (ppm)

\begin{tabular}{l|r}
30 & 60
\end{tabular}




\begin{tabular}{|c|c|c|c|c|c|c|c|c|}
\hline & Dye & $\begin{array}{c}\text { Adsorbent } \\
\text { type }\end{array}$ & $\begin{array}{c}1^{\text {st }} \\
\text { column }\end{array}$ & $\begin{array}{c}2^{\text {nd }} \\
\text { column }\end{array}$ & $\begin{array}{c}3^{\text {rd }} \\
\text { column }\end{array}$ & $\begin{array}{c}1^{\text {st }} \\
\text { column }\end{array}$ & $\begin{array}{c}2^{\text {nd }} \\
\text { column }\end{array}$ & $\begin{array}{c}3^{\text {rd }} \\
\text { column }\end{array}$ \\
\hline \multirow{4}{*}{$\begin{array}{l}\text { Adsorbed } \\
\text { dye (\%) }\end{array}$} & \multirow{2}{*}{ Green } & Orange & 98.0 & 1.5 & 0.0 & 97.5 & 2.5 & 0.0 \\
\hline & & Lemon & 90.7 & 7.7 & 1.5 & 84.0 & 13.6 & 2.1 \\
\hline & \multirow{2}{*}{ Blue } & Orange & 57.0 & 29.9 & 2.6 & 67.4 & 25.0 & 4.2 \\
\hline & & Lemon & 42.1 & 44.2 & 6.3 & 93.8 & 2.5 & 0.0 \\
\hline
\end{tabular}

